at a lower velocity, and so can be observed for a longer time. Accuracy is inversely proportional to time of observations.

These, however, may be exceptions that prove the rule. There remains broad agreement that much of the research planned for the station is likely to remain tangential to the central concerns of biomedicine and materials science. Its greatest impact will be felt in the small community already studying problems related to spaceflight — a vital research area only if we assume that increasing numbers of people will someday travel, or even live, outside of normal Earth gravity. Plant studies are likely to focus mostly on growing crops for astronaut crews. Combustion research in microgravity, while revealing some new information about the basic physics of flame propagation or turbulence, will primarily influence those who write fire safety regulations for spacecraft.

Lother Willmitzer, director of the Max Planck Institute for molecular plant physiology in Potsdam, illustrates the difficulty space experiments have in competing with ground-based research on a cost-benefit basis. Work on gravitropism, the directional growth of plant tips in response to gravity, is interesting basic biology, he says, and space experiments in this area have been well designed. At the same time, mutants of the standard reference plant Arabidopsis thaliana have been developed that have aberrant responses to gravity, causing their roots to grow in all directions. Using mutants to explore the genetic mechanisms behind the gravity response is much cheaper than rocketing an experiment into Earth orbit.

Still, the quality of space experiments is

\title{
Bartering for experimental time and space has already begun
}

The space station is proving to be a challenging experiment in international collaboration as well as being a hugely complex engineering job. "In effect, an international space agency has been created for the station," says John Logsdon, a space policy analyst at George Washington University in Washington. He points out that a 300-person multinational management group is already planning for the station's continuous use and operation.

Representatives of the 15 major station partners - the United States, Russia, Japan, Canada and 11 members of the European Space Agency (ESA) - gathered in Washington last month to approve formally the sharing of facilities on the station, from laboratory space to electrical power.

NASA, the biggest financial contributor and overall project manager, will have almost full use of its own laboratory module, plus slightly less than half of the Japanese and European research laboratories. ESA and Japan are each allocated 51 per cent of their own laboratories, and Canada 2.3 per cent of all three research modules in exchange for building the station's robot arm.

Resources such as storage space, power, and crew time also will be shared, with NASA receiving 77 per cent, Japan 13 per cent, ESA 8 per cent, and Canada 2 per cent.

These formulas apply only to the nonRussian part of the station. The project's second biggest partner in terms of hardware contributions will retain full control of its own resources, as well as of the two research modules it plans to add in 2002. Crew time will be evenly divided, with half going to Russia and half to the rest of the partners. For all practical purposes, says Logsdon, "the station is divided in two".

These, however, are only the opening positions. Bartering of time, hardware, and laboratory space has already begun before the first element is even launched. ESA, lacking any place of its own to attach exterior payloads during the early years of assembly, is building a pointing device for astronomical and Earth-observing instruments in exchange for some of NASA's

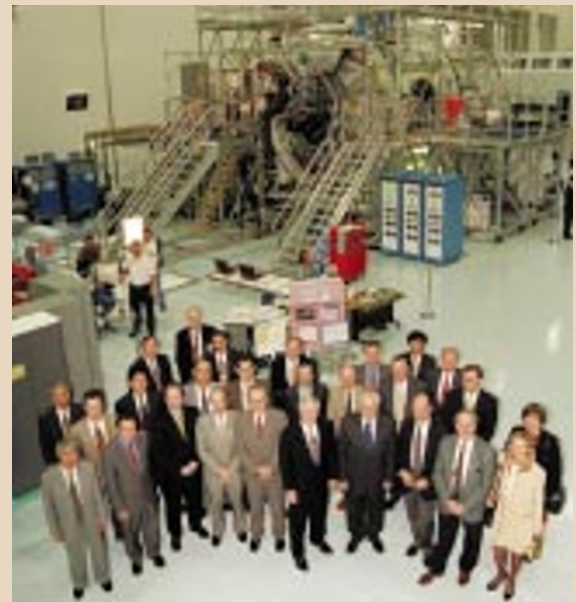

Family portrait: officials from the 15 countries that will share in running the space station.

'turf' on the outside of the station.

Brazil last year signed a bilateral agreement to provide a high-quality optical window in the 'floor' of the US laboratory, which it will trade for Earth-viewing time that had been reserved for NASA. And in a move that has upset many US scientists, Japan is to build a critical centrifuge for biological studies —which NASA had been planning to supply - to offset costs associated with using the space shuttle to deliver its laboratory module to the station in 2001 (see Nature 383, 8; 1996).

US scientists, fearing their interests were playing second fiddle to NASA's eagerness to defer any near-term cost of building research equipment, have asked to be included in any further discussions of bartering between NASA station programme managers and the international partners.

The so-called 'attached payloads' illustrate how a 'real estate market' may develop among the international partners. The NASA-owned supporting "trusses" and the Japanese laboratory both have room for mounting external payloads that have no need of pressurized conditions.

NASA has, so far, been slow to identify experiments that might occupy these prized slots. In contrast, ESA was surprised last year to receive more than 100 responses to its call for proposals for attached payloads, which included experiments in technology, Earth observation and radiation biology.

Because of the popularity of the outside slots, ESA has decided to add external pallets to its laboratory module which is scheduled for launch in 2002. Until then, European scientists will have to queue up for whatever room ESA can barter from NASA and Japan.

The first steps towards creating a unified research programme for the station have also been taken by the international partners. In 1995, after three years of negotiation, life scientists from all the relevant space agencies, including those of France, Germany, Canada, and Japan as well as NASA and ESA, agreed in principle to share all their facilities and resources and to allocate them to projects jointly assessed as the most scientifically important, regardless of geographical origin.

To this end, the International Space Life Sciences Working Group was set up. It organizes a global peer-review exercise through 14 subdiscipline-related peer-review panels. Results from the first such joint review last year surprised nearly everyone: two-thirds of the selected experiments were from outside the United States, with more than half coming from Europe.

The lopsided result poses a dilemma. European and other non-US proposals may have ranked higher, but their funding agencies - which will make the final determination of what goes on the space station - are poorer than NASA, which also owns the lion's share of station resources. Some US experiments may therefore end up flying while non-US experiments that scored higher in this first attempt at global peer review wait on the ground.

Still to be determined, too, is how active Russia's own research programme will be. The Russian space agency already has identified more than 250 investigations that could go up on the station, but money to pay for them is in short supply, Without outside support, Russia may become a laboratory owner with no researchers of its own. 